\title{
MEMBUAT APLKASI GAME KEONG MATH MENGGUNAKAN MACROMEDIA FLASH 8
}

\author{
Ricky Zulfiandry ${ }^{1}$, Rahmat Kurniawan ${ }^{2}$ \\ ${ }^{1,2}$ Program Studi Sistem Informasi Fakultas Ilmu Komputer Universitas Dehasen Bengkulu \\ Jalan Meranti Raya No.32 Kelurahan Sawah Lebar Kota Bengkulu Telp. (0736) 22027, 26957 Fax. (0736) 341139 \\ 1ricky.zulfiandry@gmail.com \\ ${ }^{2}$ rahmat_k@gmail.com
}

\begin{abstract}
Many kinds of teaching tool delivery methods or current learning methods are made in such a way as to attract the interest of learning. The use of information and communication technology today is already a mandatory thing and as our effective and efficient way to convey information or obtain information, one of which is the use of computers to present and combine text, graphics, sound, video in an integrated form and use tools that allow the user to navigate, interact, and communicate. Objectives creating a program of learning mathematics aids in the form of games, especially arithmetic to help children who are not or less enthusiasm to learn with the book media. The resulting program is made interesting and given an example of how to use it so hopefully the children can know about how to play the game and make the game as a medium of learning, research method used is by using literature study, and field study. Field study conducted, i.e. observation, interview, and documentation study. The results achieved is to create an arithmetic-based game application program that can be used as a learning tool for children in particular.
\end{abstract}

Keywords : Application of Game, Macromedia Flash

\section{INTISARI}

Banyak macam metode penyampaian informasi perangkat ajar atau metode pembelajaran saat ini dibuat sedemikian rupa guna menarik minat belajar. Penggunaan teknologi informasi dan komunikasi saat ini adalah sudah menjadi suatu hal yang wajib dan sebagai cara kita yang efektif dan efisien untuk menyampaikan informasi atau mendapatkan informasi, salah satunya Program multimedia adalah penggunaan komputer untuk menyajikan dan menggabungkan teks, grafik, suara, video dalam bentuk terpadu dan menggunakan peralatan yang memungkinkan user untuk melakukan navigasi, interaksi, dan komunikasi. Tujuan Membuat program bantu belajar matematika berbentuk game khususnya Aritmetika untuk membantu anak-anak yang tidak atau kurang semangat belajar dengan media buku. Program yang dihasilkan dibuat menarik dan diberi contoh cara menggunakannya sehingga diharapkan anak-anak dapat mengetahui tentang cara memainkan game tersebut dan menjadikan permainan sebagai media belajar, Metode Penelitian yang digunakan yaitu dengan menggunakan studi pustaka, dan studi lapangan. Cara studi lapangan yang dilakukan, yaitu observasi, wawancara, dan studi dokumentasi. Hasil yang dicapai adalah dapat membuat sebuah program aplikasi game berbasis arithmatika yang dapat dijadikan sebagai alat bantu belajar bagi anak-anak khususnya.

Kata Kunci :Aplikasi Game, Macromedia Flash

\section{PENDAHULUAN}

Teknologi informasi saat ini telah berkembang sangat pesat. Kebutuhan untuk mendapatkan informasi dengan cepat, menuntut kita untuk memanfaatkan teknologi informasi yang telah tersedia saat ini. Informasi adalah hal yang sangat berharga di era globalisasi ini. Sejak hadirnya internet, informasi tidak lagi dibatasi. Banyak macam metode penyampaian informasi perangkat ajar atau metode pembelajaran saat ini dibuat sedemikian rupa guna menarik minat belajar. Penggunaan teknologi informasi dan komunikasi saat ini adalah sudah menjadi suatu hal yang wajib dan sebagai cara kita yang efektif dan efisien untuk menyampaikan informasi atau mendapatkan informasi.
Bagi sebagian anak belajar aritmetika adalah satu hal yang sangat membosankan, apalagi dengan media yang hanya berupa buku, terkadang melihat tulisan aritmetika saja anak-anak bosan.

Berdasarkan uraian di atas, penulis membuat program berbasis multimedia sebagai alat bantu belajar Aritmetika melalui media permainan dengan tampilan yang menarik. Dengan program bantu ini diharapkan akan menjadi media belajar alternatif untuk mempelajari Aritmetika. Tujuan penelitian ini adalah membuat program bantu belajar matematika berbentuk game khususnya Aritmetika untuk membantu anak-anak yang tidak atau kurang semangat belajar dengan media buku. Program yang dihasilkan dibuat menarik dan diberi contoh cara menggunakannya sehingga diharapkan anak-anak dapat menge- 
tahui tentang cara memainkan game tersebut dan menjadikan permainan sebegai media belajar.

\section{TINJAUAN PUSTAKA}

\section{A) Pengertian Multimedia}

Multimedia adalah penggunaan komputer untuk menyajikan dan menggabungkan teks, grafik, suara, video dalam bentuk terpadu dan menggunakan peralatan yang memungkinkan user untuk melakukan navigasi, interaksi, dan komunikasi. (Sutopo, 2003: 1)

Definisi ini mengandung 4 komponen penting dalam multimedia. Pertama, komputer diperlukan untuk mengkoordinasikan apa yang dilihat dan didengar. Kedua, harus ada jalur yang menghubungkan dengan informasi. Ketiga, harus ada tabel-tabel navigasi sehingga kita dapat menjelajahi informasiinformasi yang terhubung dan yang keempat, karena multimedia bukan hanya sebagai tontonan olahraga, maka harus ada jalan untuk mengumpulkan, memproses, dan mengkomunikasikan informasi dan ideide kita. (Sutopo, 2003: 1)

\section{B) Animasi}

Animasi merupakan gambar hidup yang menayangkan frame-frame gambar secara cepat agar menghasilkan efek gerak. Ada empat jenis animasi, yaitu:

\section{1) Frame Animation}

Jenis animasi ini membuat objek bergerak dengan memperlihatkan urutan dari perpindahan gambar sehingga objek terlihat di lokasi yang berbeda pada layar.

\section{2) Vector Animation}

Vektor adalah garis yang memiliki awal, arah dan panjang. Vektor animasi membuat objek bergerak dengan menyimpangkan ketiga parameter dari segmen garis yang membatasi objek.

\section{3) Computation Animation}

Pada computation animation ini, objek dibuat bergerak melintasi layar hanya dengan menyimpangkan koordinat x dan y-nya saja. Koordinat x untuk posisi horizontal, sedangkan koordinat y untuk posisi vertical.

\section{4) Morphing}

Morphing berarti perubahan dari satu bentuk ke bentuk lainnya dengan memperlihatkan urutan pada frame sehingga menciptakan pergerakan halus dari bentuk awal ke bentuk akhir.

\section{C) Arithmatika}

Aritmetika kadang salah dieja sebagai *aritmatika* dari kata bahasa Yunani / $\alpha \rho \imath \theta \mu o ́ c /$ /arithnos/ = angka atau dulu disebut ilmu hitung merupakan cabang (atau pendahulu) matematika yang mempelajari /operasi/ dasar bilangan. Oleh orang awam, kata "aritmatika" sering dianggap sebagai sinonim dari teori bilangan. Silakan lihat angka untuk mengetahui lebih dalam tentang teori bilangan. 1. Operasi aritmatika Operasi dasar aritmatika adalah penjumlahan, pengurangan, perkalian dan pembagian, walaupun operasi-operasi lain yang lebih canggih (seperti persentase, akar kuadrat, pemangkatan, dan logaritma) kadang juga dimasukkan ke dalam kategori ini. Perhitungan dalam aritmatika dilakukan menurut suatu urutan operasi yang menentukan operasi aritmatika yang mana lebih dulu dilakukan. Aritmatika bilangan asli, bilangan bulat, bilangan rasional, dan bilangan real umumnya dipelajari oleh anak sekolah, yang mempelajari algoritma manual aritmatika. Namun demikian, banyak orang yang lebih suka menggunakan alat-alat seperti kalkulator, komputer, atau sempoa untuk melakukan perhitungan aritmatika. Perkembangan terakhir di indonesia berkembang mempelajari aritmatika dengan bantuan metoda jarimatika, yakni menggunakan jari-jari tangan untuk melakukan operasi kali-bagi-tambah-kurang.

Aritmetika adalah ilmu dasar dari matematika yang menjadi pondasi dari anak-anak dalam belajar matematika, pada bahasan ini penulis cuma membatasi untuk kelas IV sekolah dasar (SD) saja, yang meliputi: penjumlahan, pengurangan, perkalian dan pemba-gian, operasi hitung campuran,kelipatan dan faktor bilangan, pengukuran, segitiga dan jajar genjang dan bilangan bulat.

\section{D) Bagian Arithmatika \\ Operasi Hitung Bilangan}

Kita telah mengenal operasi hitung bilangan yaitu penjumlahan, pengurangan, pembagian dan perkalian. Adapun sifat-sifat yang berlaku pada operasi hitung tersebut adalah:

1) Sifat pertukaran (komutatif)

2) Sifat pengelompokan (Asosiatif)

3) Sifat penyebaran (distributif)

\section{Operasi hitung campuran}

Setelah kita mengenal operasi-operasi hitung bilangan yang meliputi penjumlahan, pengurangan, perkalian, dan pembagian.

\section{Kelipatan dan factor bilangan}

Operasi-operasi hitung tersebut harus benar-benar kita fahami karena akan kita gunakan dalam mempelajari kelipatan dan faktor bilangan sebagai berikut:

1) Kelipatan bilangan

2) Faktor persekutuan bilangan 


\section{E) Keahlian Yang Harus Dimiliki}

Berikut ini terdapat beberapa keahlian yang harus di perhatikan untuk membuat suatu game :

\section{1) Keahlian Mendesain Game}

Kita harus mengetahui psikologi manusia untuk bias memahami desain game. Dan mempelajarinya membutuhkan waktu yang cukup lama. Desain yang baik akan mempermudah programmer membuat berbagai alur permainan yang baik.

\section{2) Keahlian Grafis}

Grafis merupakan salah satu bagian yang tidak terpisahkan dari sebuah game. Kemampuan grafis erat hubungannya dengan seni dan bakat. Semakin banyak aplikasi grafis yang kita kuasai akan memudahkan kita untuk bekerja dibidang ini.

\section{3) Keahlian Editing Audio}

Dengan audio game yang dimainkan akan terasa lebih hidup. karena game terdiri dari bermacam suara dan efeknya.

\section{F) Konsep Game}

Konsep dalam game sangat kita perlukan dalam pembuatan suatu game karena kita akan menjadi lebih mengerti tentang apa arti dari game tersebut.

\section{1) Introduksi ( Perkenalan )}

Menjelaskan isi dan sifat daripada game yang dibuat, mencoba menguraikan game seolah-olah game tersebut menarik. Ini dapat dilakukan dari pembuatan judul, gaya, arah, dan pengaturan. Pada intinya visi dan misi harus jelas.

\section{2) Background ( Latar Belakang )}

Biasanya terpisah dari bagian introduksi, sehingga bias langsung diabaikan oleh user jika sudah merasa cukup mendapat informasi dari introduksi. Berisi penjelasan tentang pengembangan atau konsep yang sama dari game yang telah dirilis sebelumnya.

\section{3) Dipenelitian}

Menjelaskan game kepada User, seolah-olah mereka sebagai pemain. Gunakan sudut pandang orang kedua (anda atau kamu ). Buatlah semenarik mungkin agar pemain game benar-benar masuk dalam karakter yang telah kita ciptakan.

\section{4) Komponen Kunci}

Dalam game yang kita desain biasanya terdapat komponen-komponen penting yaitu Artificial intelegence (kecerdasan buatan), tampilan grafis yang menarik, serta penataan music.

\section{5) Corak Game}

Menjelaskan termasuk dalam klasifikasi yang mana game yang kita buat. Apakah olahraga, strategi, puzzle, balapan, atau petualangan. Dengan menonjolkan sesuatu agar kelihatan mempunyai nilai lebih, sebagai contoh dengan kita menonjolkan tampilan grafisnya.

\section{6) Platform}

Penjelasan target platform, apakah hanya untuk single user atau sudah mampu mendukung multiplayer.

\section{G) Desain Game}

Ada beberapa hal mendasar yang harus diperhatikan dalam mendesain suatu game, agar bias mendapatkan hasil yang maksimal yaitu :

1) Mekanisme Game

2) Inti Permainan Game

3) Alur game

4) Karakter

5) Elemen Permainan Game

6) Statistik Dan Fisik Game

7) Artificial intelligence ( Kecerdasan Buatan )

8) Multiplayer

9) User Interface

10) Seni dan Video

11) Seni 2D ( Dua Dimensi ) dan Animasi

12) Seni 3D (Tiga Dimensi ) dan Animasi

13) Sinematik

14) Sound Effect ( efek suara )

15) Musik

\section{H) Macam-macam Game}

Berdasarkan jenisnya game dapat di golongkan menjadi beberapa macam, menurut cara bermain dan medannya.
1) Maze Game
2) Board Game
3) Card Game
4) Battle Card Game
5) Quiz Game
6) Puzzle Game
7) Shoot Them Up
8) Sice Scroller Game
9) Fighting Game
10) Racing Game
11) Flight Sim
12) Turn-Based Strategy Game
13) Real-Time Strategy Game
14) First Person Shooter
15) Third Person 3D Games
16) Role Playing Games
17) Adventure Game
18) Full Motion Video Game
19) Educational and Edutainment.
20) Sport 


\section{I) Terlibat Dalam Game}

Saat ini bisnis game bukan bisnis kecil lagi bahkan persaingannya sudah sangat tajam dan biaya pembuatannya bisa memakan jutaan diolar. Tentu saja ada beberapa pihak yang terlibat didalam pembuatannya. Diantaranya adalah sebagai berikut :

1) Designer

2) Programmer

3) Artis

4) Audio Design

5) Producer

6) Tasting and Quality Assurance

\section{METODOLOGI PENELITIAN}

\section{A) Perancangan Sistem}

1) Gambaran Aplikasi

Dengan Aplikasi Game Aritmetika ini diharapkan anak-anak dapat mempelajari sendiri ilmu aritmetika kapanpun dan dimanapun tanpa harus didampingi oleh pengajar. Karena pada Aplikasi Game Aritmetika ini disertai dengan cara menjawab. User hanya perlu menggunakan mouse dan keyboard dan memilih (klik) pada tombol menu-menu yang tersedia, kemudian menjawab soal-soal yang muncul ketika actor dalam game ini(keong) menabrak halangan yang disini berupa kayu.

Ketika pertama kali menjalankan aplikasi ini tampilan yang muncul adalah opening program yang selanjutnya masuk ke halaman utama. Pada halaman utama terdapat empat tombol, yaitu tombol tutorial, tombol profil, tombol petunjuk/cara main, tombol mulai, dan tombol keluar/close. Tombol tutorial menuju ke halaman yang berisi tutorial atau materi yang di ujikan dalam permainan. Tombol profil menuju ke halaman yang berisi depenelitian pembuat. Tombol petunjuk menuju ke halaman yang berisi petunjuk umum menjalankan program. Tombol mulai menuju ke halaman permainan dan tombol keluar untuk menutup aplikasi.

Aplikasi Game Aritmatika ini dirancang manggunakan Macromedia Flash Professional 8 sebagai program utama, dan Adobe Photoshope CS untuk membuat tampilan background sehingga diharapkan menghasilkan tampilan yang menarik dan tidak membosankan.

\section{2) Desain Sistem}

\section{Diagram Materi Pembelajaran Arithmatika}

Diagram materi pembelajaran Aritmatika memberikan gambaran tentang materi yang disajikan pada Aplikasi Game Keong Math.

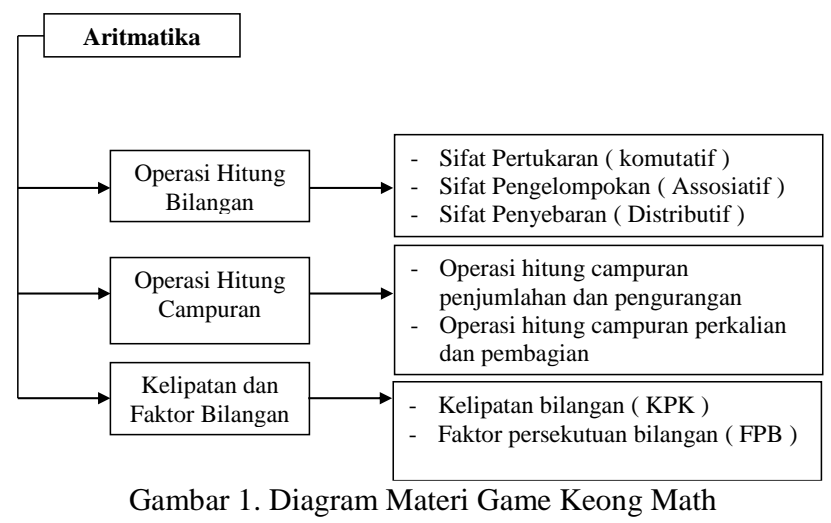

Flowchart Program/Alur Aplikasi Game

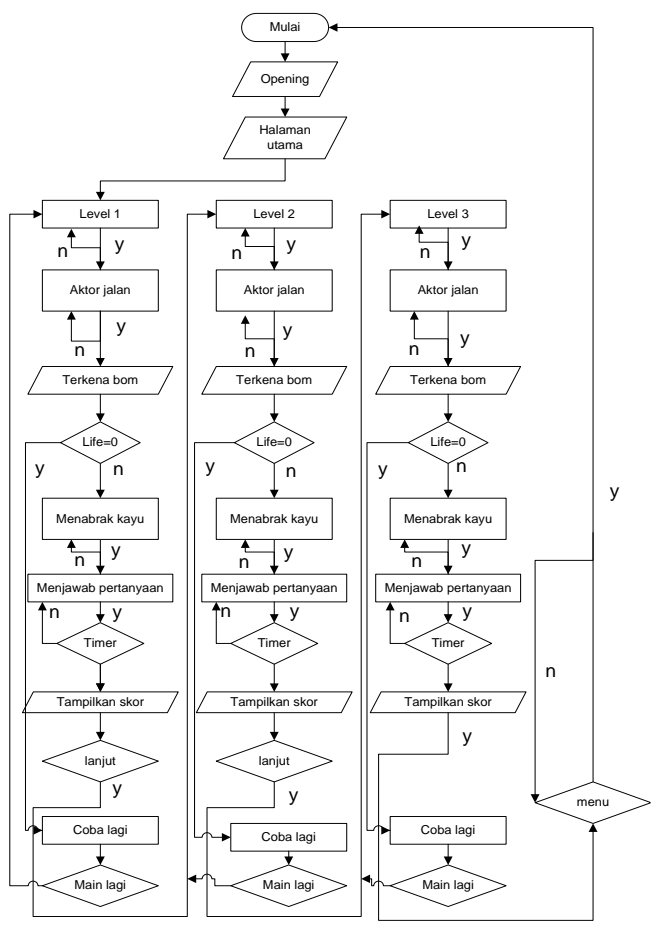

Gambar 2. Flowchart Program

Desain Aplikasi Game

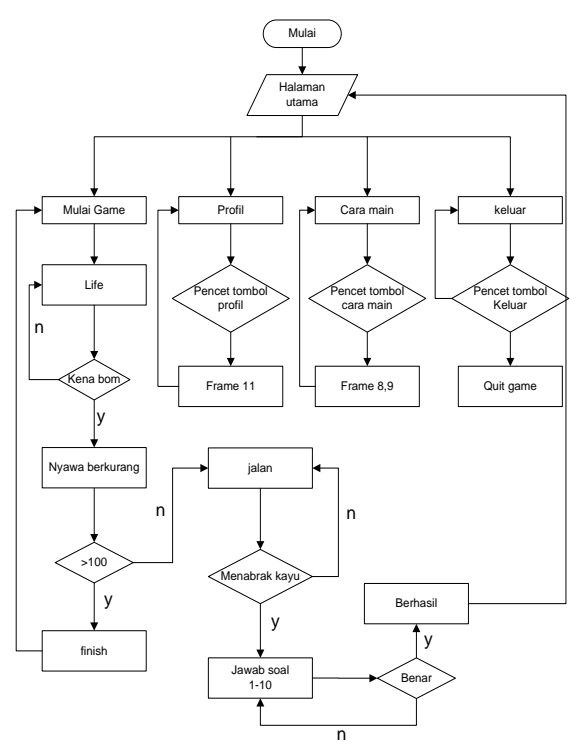

Gambar 4 Desain aplikasi game 
Desain Interface

Desain Interface Halaman Utama

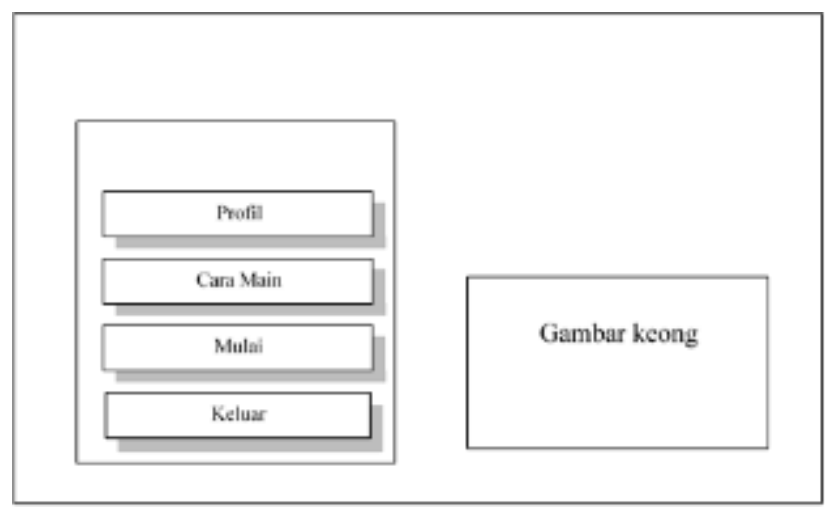

Gambar 5 Desain Interface Halaman Utama

\section{Desain Interface Profil}

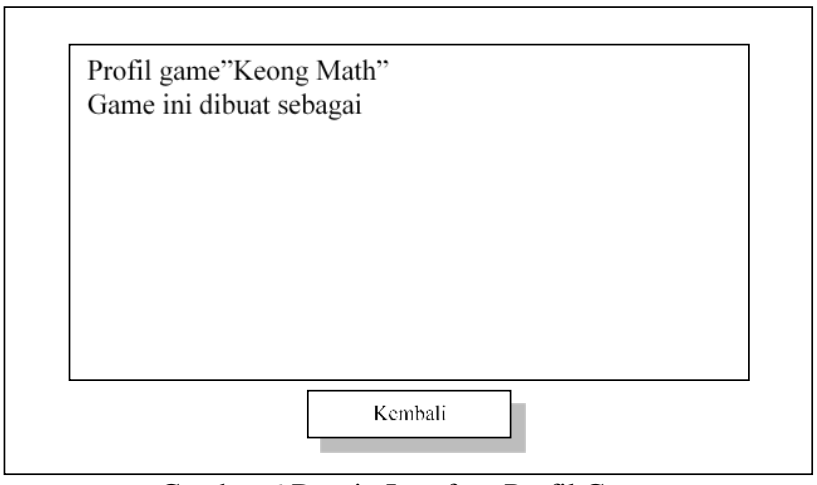

Gambar 6 Desain Interface Profil Game

\section{Desain Interface Cara Main}

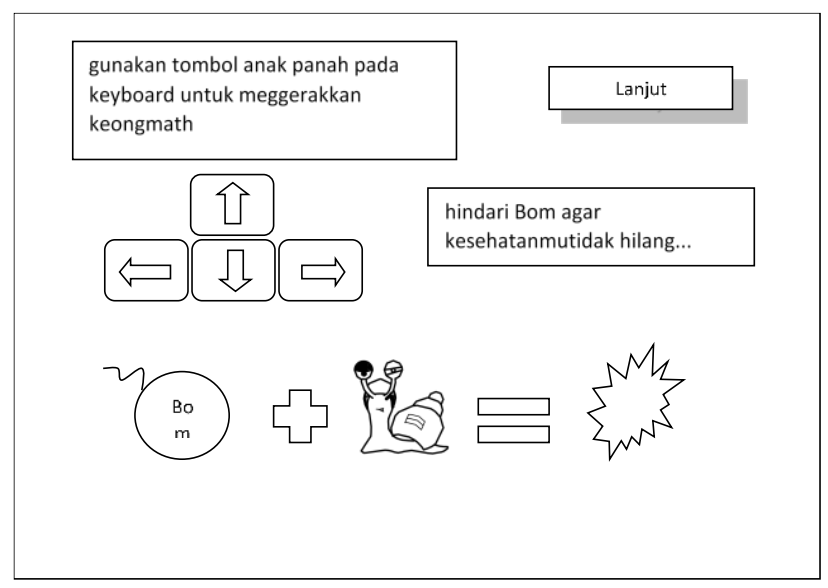

Gambar 7 Desain Interface Cara Main

Pada halaman cara main berisi petunjuk cara menjalankan game, dan terdapat satu tombol lanjut untuk melanjutkan ke halaman selanjutnya.

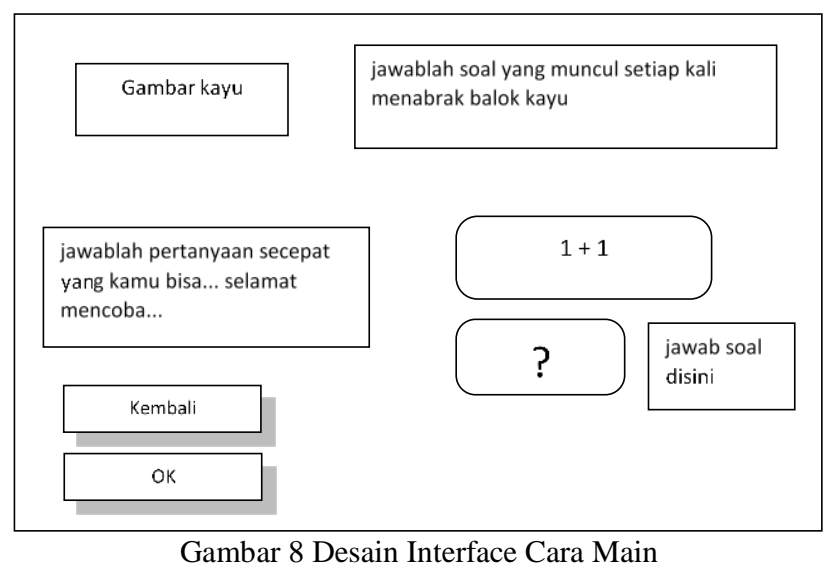

Desain Interface Mulai Permainan

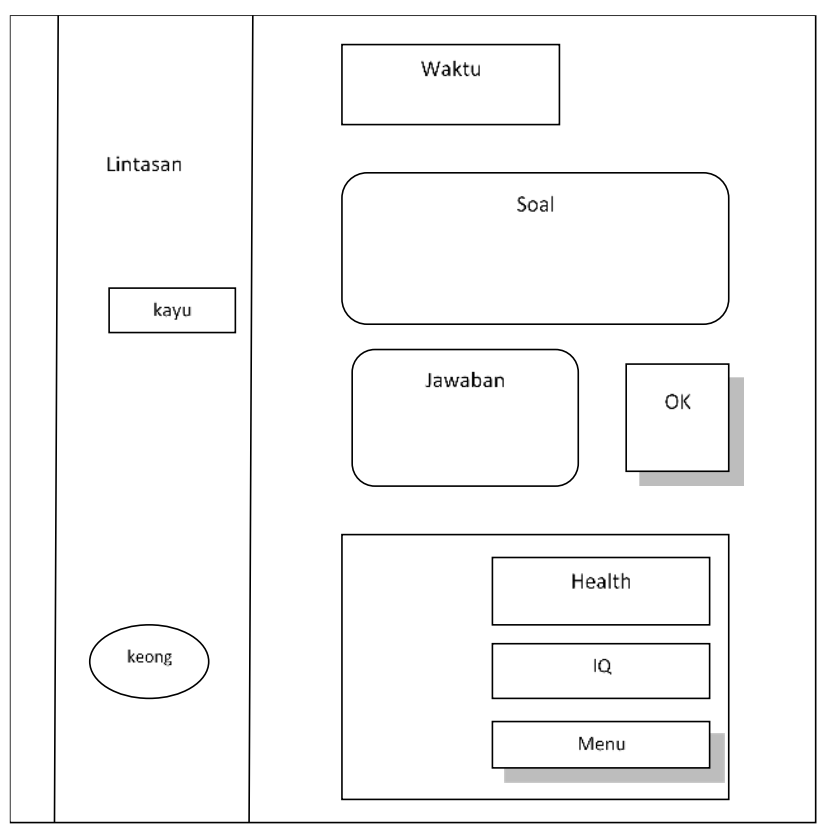

Gambar 9 Desain Interface Mulai Permainan

Keterangan gambar :

- Kotak waktu menampilkan kecepatan waktu yang di tempuh aktor dalam mencapai finish atau game over.

- Kotak soal berisi pertanyaan yang akan muncul jika aktor menabrak kayu.

- Kotak jawaban berfungsi untuk memasukan atau menginputkan jawaban yang muncul pada kotak soal juga berfungsi sebagai pemberitahuan jika jawaban benar atau salah. Jika benar maka aktor akan melanjutkan perjalanan, tetapi jika salah aktor akan tertahan pada rintangan itu sampai bisa menjawab.

- Kotak health menampilkan nyawa aktor.

- Kotak IQ berfungsi hanya sebagai pemanis tampilan game.

- Kotak menu berfungsi untuk kembali pada tampilan awal. 
Desain Interface Berhasil dan Gagal

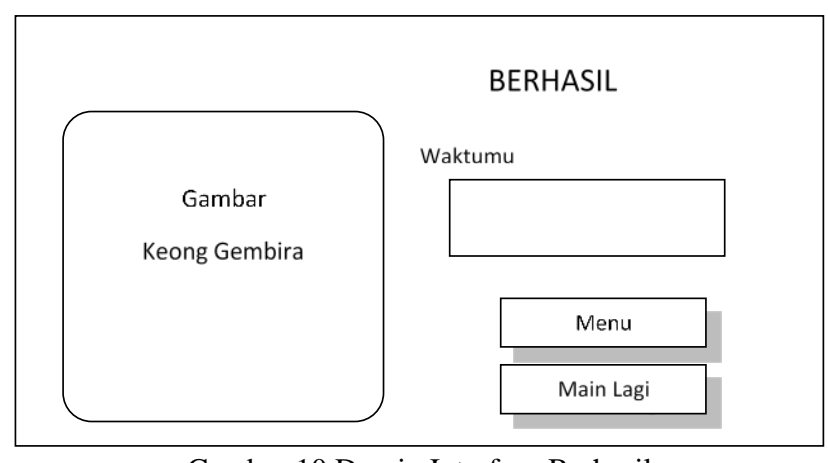

Gambar 10 Desain Interface Berhasil

Setelah keong berhasil melewati rintangan pada level 1 maka menuju ke level 2, yang waktunya lebih dipercepat.

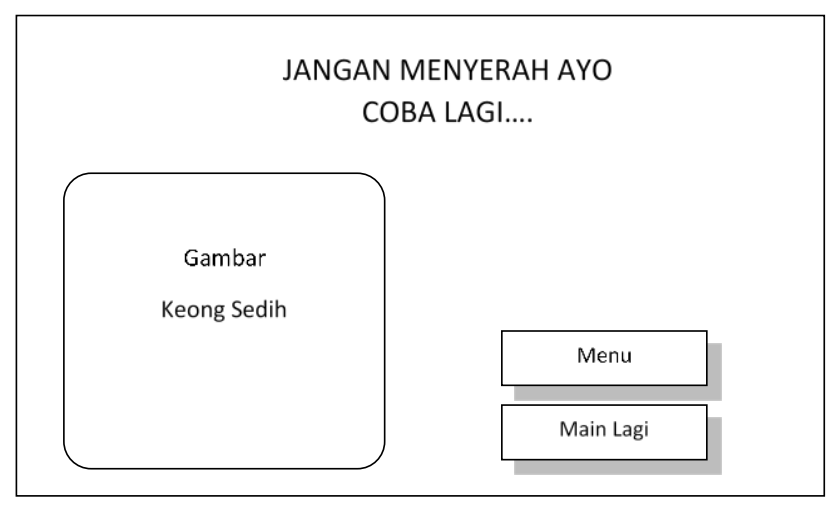

Gambar 11 Desain Interface Gagal

\section{B) Perancangan Pengujian}

Pengujian black-box berfokus pada persyaratan fungsional perangkat lunak. Dengan demikian, pengujian black-box memungkinkan perekayasa perangkat lunak mendapatkan serangkaian kondisi input yang sepenuhnya menggunakan semua peryaratan fungsional untuk suatu program. Pengujian black-box bukan merupakan alternatif dari teknik white-box tetapi merupakan pendekatan komplementer yang kemungkinan besar mampu mengungkap kelas kesalahan daripada metode whitebox. Pengujian black-box berusaha menemukan kesalahan dalam kategori sebagai berikut :

- Fungsi-fungsi yang tidak benar atau hilang

- Kesalahan interface

- Kesalahan dalam struktur data atau akses database eksternal

- Kesalahan kinerja

- Inisialisasi dan kesalahan terminasi

Tidak seperti pengujian white box yang dilakukan pada awal proses pengujian, pengujian black box cenderung diaplikasikan selama tahap akhir pengujian. Karena pengujian black box memperhatikan struktur kontrol, maka perhatian berfokus pada domain informasi. Pengujian didesain untuk menjawab pertanyaan-pertanyaan berikut :

- Bagiamana vaiditas fungsional diuji ?

- Kelas input apa yang akan membuat test cse menjadi baik?

- Apakah sistem sangat sensitifterhadap harga input tertentu?

- Bagaimana batasan dari suatu data diisolasi ?

- Kecepatan data apa dan volume data apa yang dapat ditolerir oleh sistem ?

- Apa pengaruh kombinasitertentu dari dataterdahap operasi sistem ?

Dengan mengaplikasikan teknik black box, maka kita menarik serangkaian test case yang memenuhi kriteria berikut ini:

- Test case yang mengurangi, dengan harga lebih dari saatu, jumlah test case tambahan yang harus didesain untuk mencapai pengujian yang dapat dipertanggungjawabkan.

- Test case yang memberi tahu kita sesuatu mengenaikehadiran atau ketidakhadiran kelas kesalahan daripada memberi tahu kesalahan yang berhubugnan hanya dengan pengujian spesifik yang ada.

Rencana pengujian selengkapnya dapat dilihat pada Tabel 1.

\section{PEMBAHASAN}

\section{A) Pembahasan Sistem}

Objek tentu saja merupakan hal yang tidak dapat terlepas dari suatu game, semakin kreatif objek yang dibuat maka akan semakin menarik game untuk dimainkan. Begitu juga dengan Game Keong Math ini, ada bermacam objek yang ada diantaranya objek background, objek keong, objek bom, objek kayu, objek health, objek IQ, dan objek suara.

\section{B) Objek Background Background Menu Awal Game}

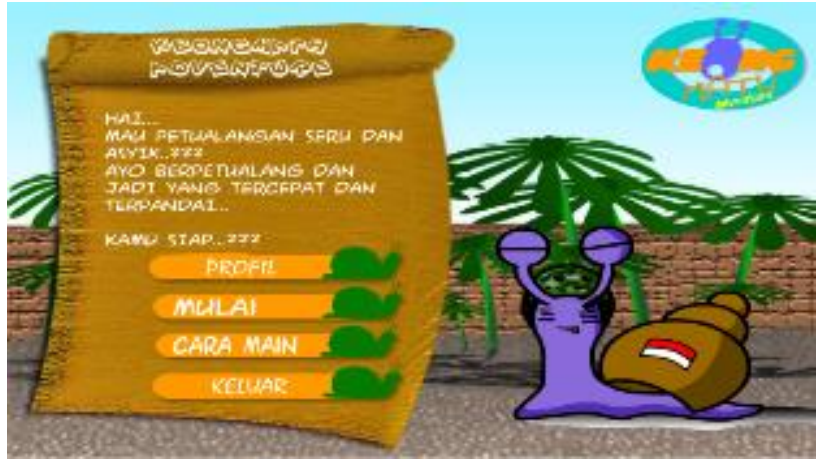

Gambar 12 Background Menu Awal Game

Terdapat dalam tampilan depan pada saat game di eksekusi, terdiri dari empat frame. Tampilan ini pada 
Tabel 1 Rencana Pengujian Aplikasi Game Keong Math.

\begin{tabular}{|c|c|c|c|}
\hline No & Komponen yang di Uji & Detail Pengujian & Jenis $\mathrm{Uji}$ \\
\hline \multirow{4}{*}{1} & \multirow{4}{*}{ Menu Awal Game } & Menampilkan menu profil & Black-box \\
\hline & & Menampilkan menu mulai game & Black-box \\
\hline & & Menampilkan menu panduan cara main game & Black-box \\
\hline & & Menampilkan menu keluar game & Black-box \\
\hline \multirow[b]{2}{*}{2} & \multirow[b]{2}{*}{ Menu Profil } & Menampilkan tombol pilihan Ok & Black-box \\
\hline & & Menampilkan tombol pilihan kembali & Black-box \\
\hline \multirow{4}{*}{3} & \multirow{4}{*}{ Menu Mulai Game } & Menampilkan tombol pilihan lanjut & Black-box \\
\hline & & Menampilkan tombol pilihan Ok & Black-box \\
\hline & & Menampilkan tombol pilihan main & Black-box \\
\hline & & Menampilkan tombol pilihan menu & Black-box \\
\hline \multirow{7}{*}{4} & \multirow{7}{*}{ Menu Cara Main } & Tombol arah atas & Black-box \\
\hline & & Tombol arah bawah & Black-box \\
\hline & & Tombol arah kiri & Black-box \\
\hline & & Tombol arah kanan & Black-box \\
\hline & & Tombol pilihan lanjut & Black-box \\
\hline & & Tombol pilihan kembali & Black-box \\
\hline & & Tombol pilihan Ok & Black-box \\
\hline \multirow[b]{2}{*}{5} & \multirow[b]{2}{*}{ Tampilan Kalah } & Tombol pilihan kembali & Black-box \\
\hline & & Tombol pilihan Ok & Black-box \\
\hline \multirow{3}{*}{6} & \multirow{3}{*}{ Tampilan Berhasil } & Tombol pilihan menu & Black-box \\
\hline & & Tombol pilihan main lagi & Black-box \\
\hline & & Tombol pilihan lanjut & Black-box \\
\hline
\end{tabular}

frame ketiga dan terdapat empat button yaitu profil, cara main, mulai, dan keluar.

\section{Background Profil Game}

Tampilan ini terdapat pada frame ke sebelas dan terdapat dua button yaitu OK untuk menuju ke text intro dan button KEMBALI untuk kembali ke menu awal.
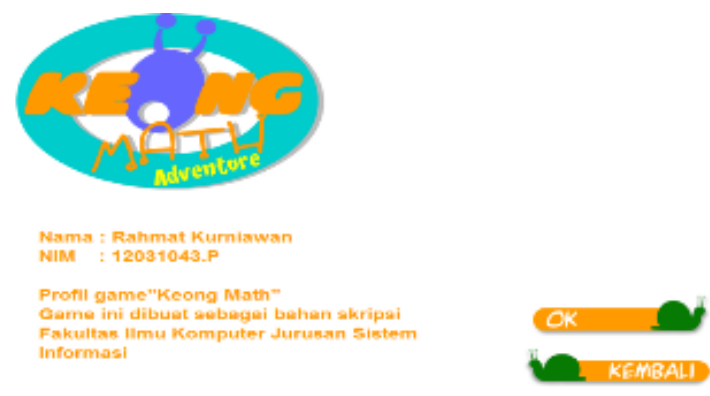

Gambar 13 Background Profil Game
Jika pada gambar 13 diatas pada button OK di eksekusi maka akan menuju ke tampilan text intro yang terletak pada frame 2 berikut ini.

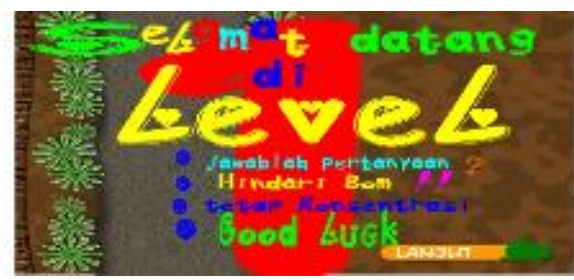

Gambar 13 Background Text Intro level 1

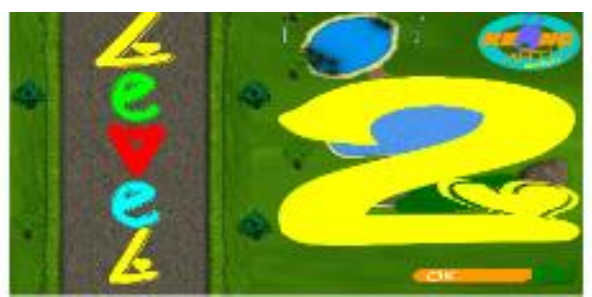

Gambar 14 background text intro level 2 


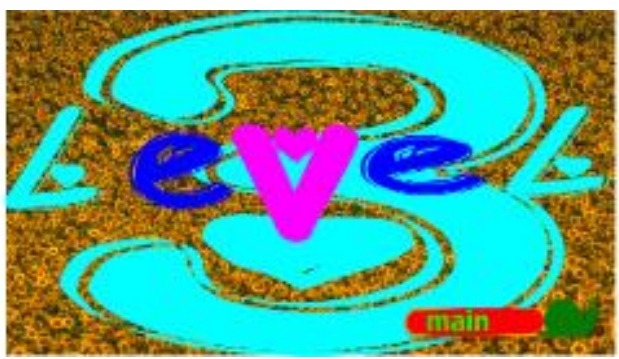

Gambar 15 Background text intro level 3

\section{Background Mulai Game}

Pada tampilan mulai ini terdapat tiga background tampilan yang terdiri dari level1, level2, dan level3. Yang mana user tidak bias mengakses level selanjutnya jika belum menyelesaikan level 1 .

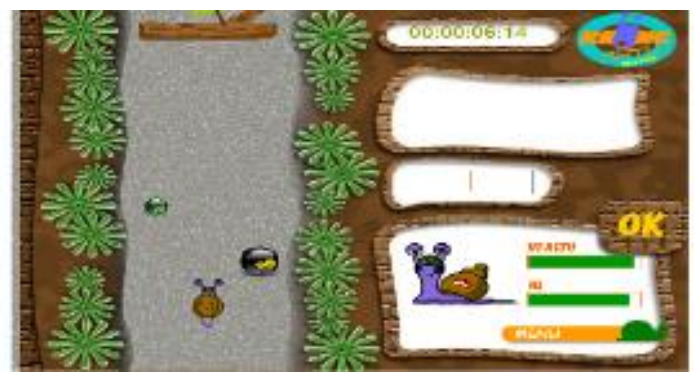

Gambar 16 tampilan Background Level 1

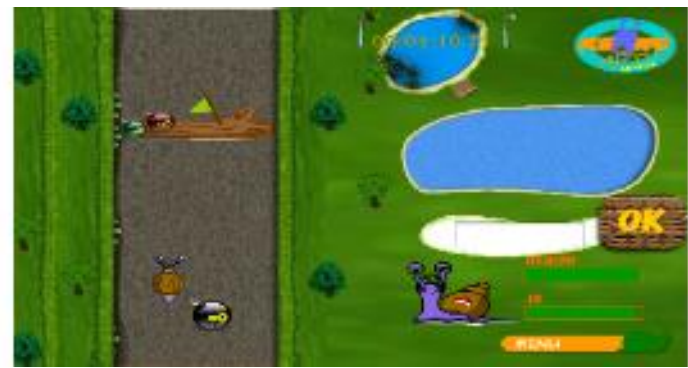

Gambar 17 tampilan Background level 2

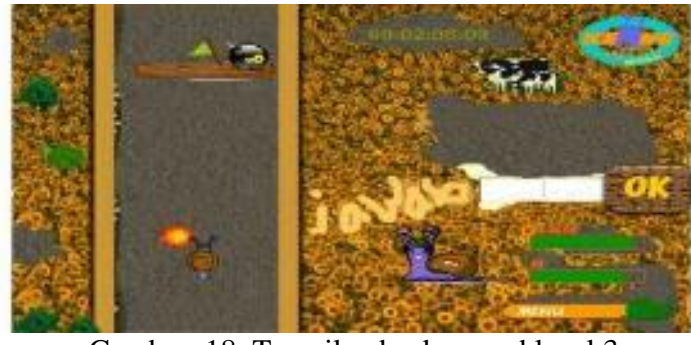

Gambar 18 Tampilan background level 3

Tampilan background level 1 terletak pada frame 5 , scene 1 , tampilan background level 2 terletak pada frame 5 , scene 2, tampilan background level 3 terletak pada frame 5 , scene 3 .

\section{Background Cara Main}

Pada tampilan ini berisi petunjuk cara menggunakan kursor keyboard untuk menjalankan Game Keong Matt. Tampilan background cara main terdapat pada frame 8 dan frame 9 .

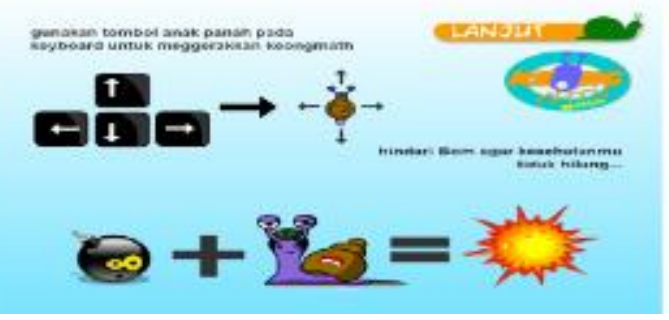

Gambar 19 Tampilan background cara main

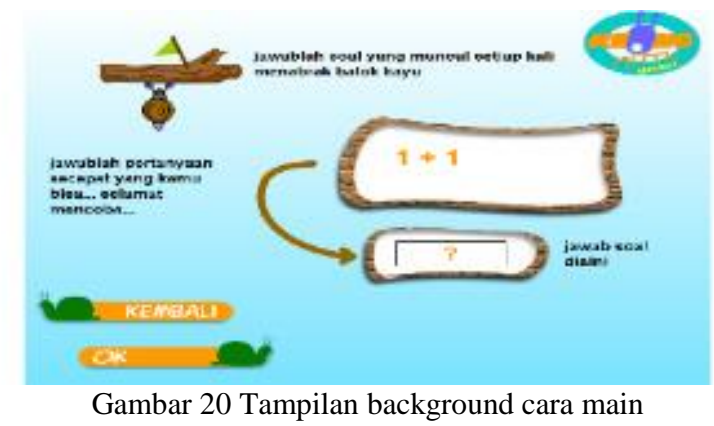

\section{Background Kalah}

Tampilan ini akan muncul ketika keong kehabisan nyawa karena terkena bom. Pada tampilan ini terdapat dua button yaitu button MENU dan button COBA LAGI.

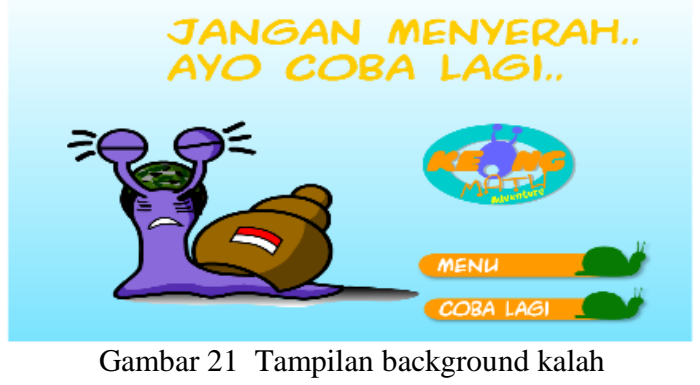

Background Berhasil

Tampilan ini akan muncul ketika misi keong telah selesai yaitu menjawab pertanyaan dan menghindari bom. Tampilan ini berada pada Frame 6 dari masingmasing level.

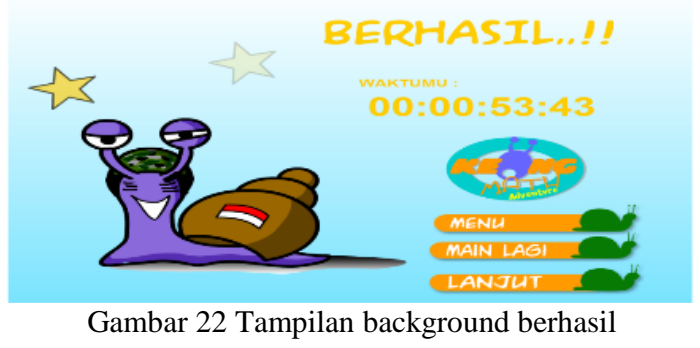

\section{C) Objek Bervariabel}

Objek bervariabel merupakan movie clip yang di dalamnya terdapat text bertipe dynamic text, sehingga isinya dapat berubah-ubah dengan action yang di tunjukan padanya, sesuai kebutuhan pada game. Action tidak kami letakkan pada objek bervariabel ini melainkan pada objek lain, dimana saat objek lain 
tersebut berubah kondisinya maka berubah pula nilai pada objek bervariabel ini.

\section{Objek timer}

Objek timer, kami menggunakan objek ini sebagai pengingat agar supaya waktu yang di tempuh user bisa seminimal mungkin, karena game ini memang di buat untuk mengasah kemampuan user dalam hal kecepatan menjawab pertanyaan. Kami berikan instance name timer dengan nama time, di gunakan sebagai tempat penyimpanan nilai waktu pada game. Objek timer terletak pada halaman mulai yaitu pada frame 5 bagian atas.

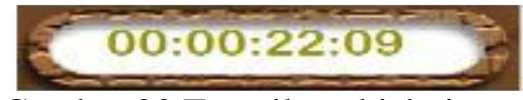

Gambar 23 Tampilan objek timer

\section{Objek soal}

Objek soal, kami berikan instance name objek soal dengan nama soal area, di gunakan sebagai indikasi apabila keong atau player menabrak halangan atau kayu. Apabila soal keluar pada soal area maka user harus menjawabnya dahulu agar kayu atau halangan hilang dan dapat menuju ke level selanjutnya.

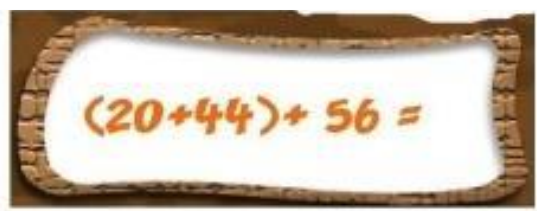

Gambar 24 Tampilan objek soal

Objek jawab

Objek jawab, kami berikan instance name dengan nama jawab area, di gunakan untuk menjawab pertanyaan yang muncul pada soal area.

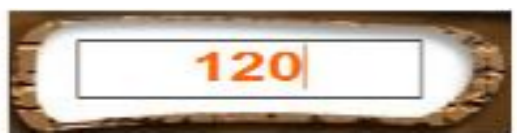

Gambar 25 Tampilan objek jawab

Apabila jawaban user salah maka akan muncul tampilan peringatan pada samping tampilan objek soal seperti berikut ini.

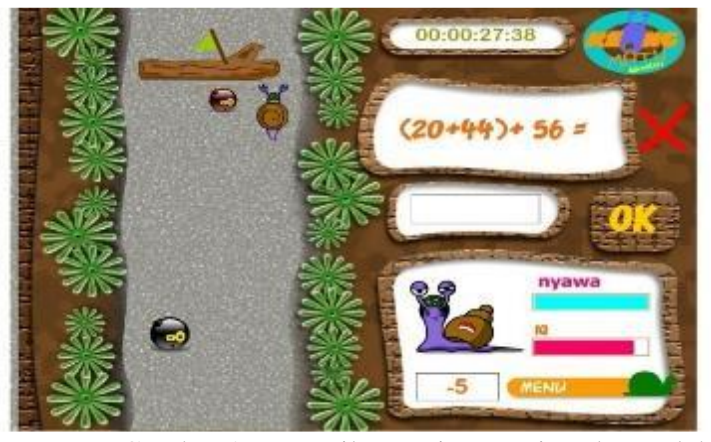

Gambar 26 Tampilan Peringatan jawaban salah
Apabila jawaban user benar maka akan muncul tampilan peringatan pada samping tampilan objek soal seperti berikut ini.

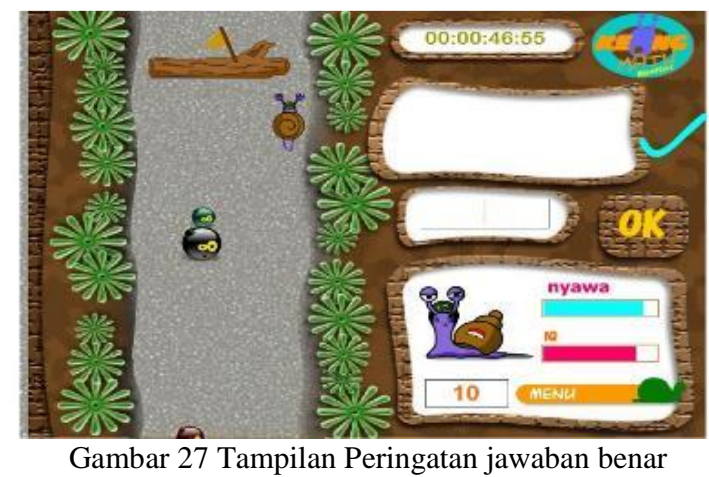

Jika jawaban user benar maka soal pada area soal akan hilang dan muncul peringatan seperti gambar di atas. Soal berikutnya akan muncul ketika keong menabrak kayu yang selanjutnya.

\section{Objek Nyawa}

Objek Nyawa ini terdiri dari dua bagian yaitu berupa movie clip, objek yang satu kita kasih nama healtbar dan yang satunya kita kasih nama borderhealth. Adapun fungsi dari borderhealth itu sendiri adalah untuk membatasi gerakan oleh healthbar ketika player menabrak bom. Jika healtbar habis maka akan selesai permainan game.

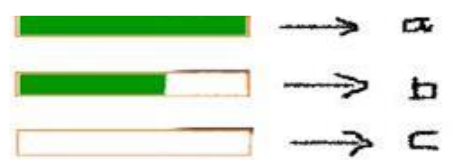

Gambar 28 Tampilan objek nyawa

\section{D) Objek Player}

Objek player ini berupa keong yang di buat dengan bentuk movie clip, objek player ini di jalankan dengan keyboard, seperti pada gambar 29.

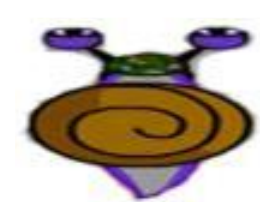

Gambar 29 Tampilan objek Player

\section{E) Objek Assets}

Objek assets ini terdiri dari beberapa bagian antara lain bom, kayu, dan soal pertanyaan. Yang mana semuanya kami kumpulkan dalam satu frame, yaitu frame lima.

\section{Objek bom}

Objek bom di sini adalah objek yang harus di hindari oleh player, karena jika player menabrak bom maka Nyawa akan berkurang. 


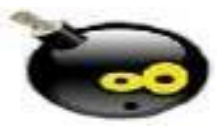

Gambar 30 Tampilan objek bom

Apabila bom mengenai player atau keong maka akan muncul efek api seperti gambar berikut ini.

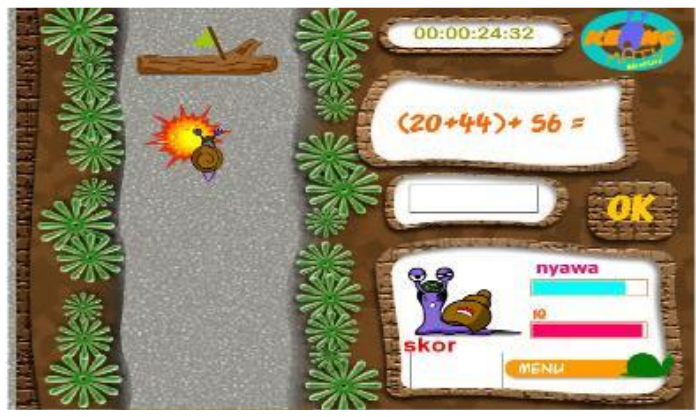

Gambar 31 Tampilan Efek bom

\section{Objek kayu}

Objek kayu di sini adalah berfungsi untuk menghalangi jalannya player menuju ke level selanjutnya, objek kayu akan hilang jika user bisa menjawab pertanyaan yang muncul ketika player menabrak kayu. Semakin cepat user menjawab pertanyaan maka akan semakin cepat juga kayu-kayu yang tersedia cepat habis dan menuju ke level selanjutnya. Untuk objek kayu kami menyimpannya di stage sebelah halaman utama game.

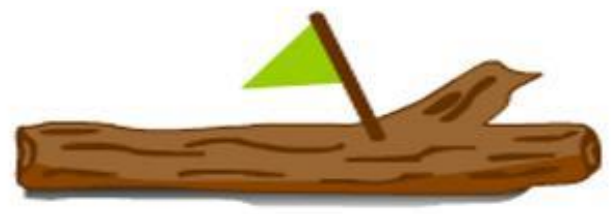

Gambar 32 Tampilan objek kayu

\section{Objek pertanyaan}

Objek pertanyaan ini kami kasih instance name dengan nama soal_one sampai soal_ten. Objek pertanyaan ini akan muncul pada area soal ketika player menabrak kayu.

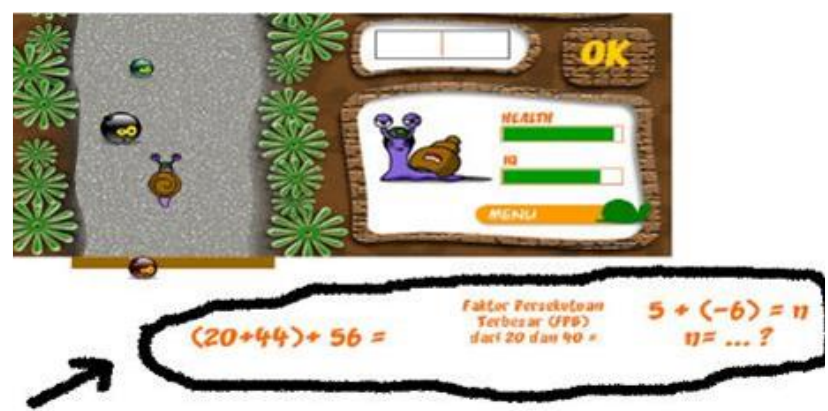

Gambar 33 Tampilan objek pertanyaan

\section{F) Objek Sound}

Objek sound atau suara digunakan agar game yang dimainkan dapat terasa lebih nyata dan lebih hidup, bahkan dapat mempengaruhi kondisi emosi user saat mendengarkan music background pada game, untuk pembuatannya sendiri bisa melalui recording dengan software audacity atau dengan mengimport langsung dari komputer ke library. Untuk bentuk format sound bisa berupa mp3 ataupun wav.

Jika menemui kesulitan dalam mencari sound music yang sesuai dengan keinginan, dapat dilakukan dengan software Wavepad. Wafepad yaitu software yang di gunakan untuk memotong lagu ataupun musik, import lagu atau music ke wavepad kemudian potong sesuai dengan keinginan dan menggantinya dengan format music yang diinginkan, bisa berupa mp3 ataupun wav.

Inilah salah satu kemudahan macromedia flash dalam mencantumkan atau mengimport lagu ataupun music. Untuk lebih jelasnya kita lihat pada gambar di bawah ini

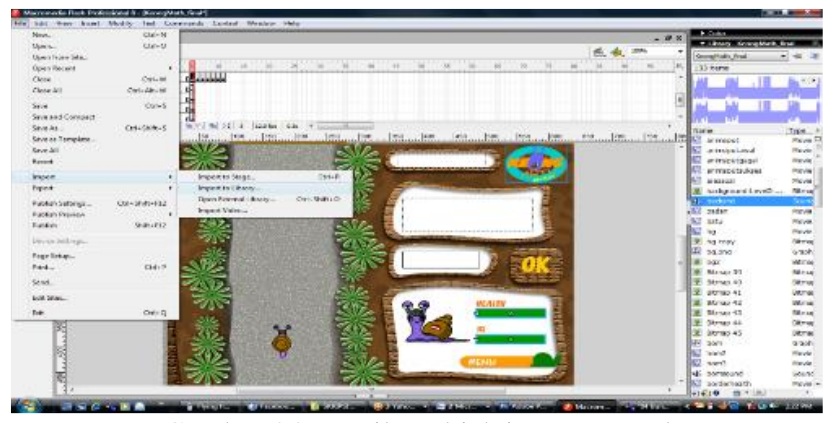

Gambar 34 tampilan objek import sound

\section{G) Hasil Pengujian}

Tabel 3 menujukkan hasil pengujian sistem aplikasi game yang telah dibangun menggunakan Macromedia Flash 8 dan di ujikan melalui metode black-box.

\section{PENUTUP}

\section{A) Kesimpulan}

Berdasarkan pembahasan pada bab-bab sebelumnya maka dapat ditarik kesimpulan yang diperoleh dari uraian mengenai Software Game Aritmetika "Keong Matt" adalah:

1) Metode Game multimedia merupakan salah satu alternatife user untuk belajar. Khususnya Game Aritmetika.

2) Dengan media Game interaktif ini siswa dapat belajar dengan mudah, karena interface yang ditampilkan berupa animasi yang menarik.

3) Berdasarkan hasil pengujian software, user dapat memahami dengan mudah dan user dapat mengerjakan soal yang disediakan di dalam game. Respon Game pada media ini cukup baik.

4) Media Game ini dirancang dengan "user interface" yang sederhana, sehingga user tidak mengalami kesulitan dalam penggunannya 
Tabel 3 Hasil Pengujian Aplikasi Game Keong Math

\begin{tabular}{|c|c|c|c|c|}
\hline No & Kasus/ diuji & Skenario Uji & Hasil Yang Diharapkam & Hasil Pengujian \\
\hline \multirow{4}{*}{1} & \multirow{4}{*}{ Menu Awal Game } & Memilih tombol profil & Menampilkan menu profil & $\begin{array}{l}\text { [ل] Berhasil } \\
\text { [] Tidak berhasil }\end{array}$ \\
\hline & & Memilih tombol memulai game & $\begin{array}{l}\text { Menampilkan dan memulai } \\
\text { game }\end{array}$ & $\begin{array}{l}\text { [V] Berhasil } \\
\text { [] Tidak berhasil }\end{array}$ \\
\hline & & Memilih tombol cara main & $\begin{array}{l}\text { Menampilkan panduan cara } \\
\text { main game }\end{array}$ & $\begin{array}{l}\text { [〕] Berhasil } \\
\text { [] Tidak berhasil }\end{array}$ \\
\hline & & Memilih tombol keluar & Keluar game / berhenti main & $\begin{array}{l}\text { [ل] Berhasil } \\
\text { [] Tidak berhasil }\end{array}$ \\
\hline \multirow[b]{2}{*}{2} & \multirow[b]{2}{*}{ Menu Profil } & Memilih tombol Ok & Menuju Text intro & $\begin{array}{l}\text { [〕] Berhasil } \\
\text { [] Tidak berhasil }\end{array}$ \\
\hline & & Memilih tombol kembali & Kembali ke menu awal & $\begin{array}{l}\text { [〕] Berhasil } \\
\text { [] Tidak berhasil }\end{array}$ \\
\hline \multirow{4}{*}{3} & \multirow{4}{*}{ Menu Mulai Game } & Memilih tombol lanjut & Menampilkan awal game & $\begin{array}{l}\text { [V] Berhasil } \\
\text { [] Tidak berhasil }\end{array}$ \\
\hline & & Memilih tombol Ok & Menampilkan lanjutan game & $\begin{array}{l}\text { [〕] Berhasil } \\
\text { [] Tidak berhasil }\end{array}$ \\
\hline & & Memilih tombol main & Menampilkan permainan game & $\begin{array}{l}\text { [〕] Berhasil } \\
\text { [] Tidak berhasil }\end{array}$ \\
\hline & & Memilih tombol menu & Kembali ke menu utama & $\begin{array}{l}\text { [〕] Berhasil } \\
\text { [] Tidak berhasil }\end{array}$ \\
\hline \multirow{7}{*}{4} & \multirow{5}{*}{ Menu Cara Main Game } & Memilih tombol atas & Menuju arah atas & $\begin{array}{l}\text { [ل] Berhasil } \\
\text { [] Tidak berhasil }\end{array}$ \\
\hline & & Memilih tombol arah bawah & Menuju arah bawah & $\begin{array}{l}\text { [〕] Berhasil } \\
\text { [] Tidak berhasil }\end{array}$ \\
\hline & & Memilih tombol arah kiri & Menuju arah kiri & $\begin{array}{l}\text { [〕] Berhasil } \\
\text { [] Tidak berhasil }\end{array}$ \\
\hline & & Memilih tombol arah kanan & Menuju arah kanan & $\begin{array}{l}{[\sqrt{]} \text { Berhasil }} \\
\text { [] Tidak berhasil }\end{array}$ \\
\hline & & Memilih tombol lanjut & Melanjutkan game & $\begin{array}{l}\text { [V] Berhasil } \\
\text { [] Tidak berhasil }\end{array}$ \\
\hline & & Memilih tambol Kembali & Kembali ke menu awal & $\begin{array}{l}\text { [〕] Berhasil } \\
\text { [] Tidak berhasil }\end{array}$ \\
\hline & & Memilih tombol Ok & Menuju Text intro & $\begin{array}{l}\text { [ل] Berhasil } \\
\text { [] Tidak berhasil }\end{array}$ \\
\hline \multirow[t]{2}{*}{5} & \multirow[t]{2}{*}{ Menu Tampilan Kalah } & Memilih tombol kembali & Menuju kembali main game & $\begin{array}{l}\text { [〕] Berhasil } \\
\text { [] Tidak berhasil }\end{array}$ \\
\hline & & Memilih tombol Ok & Menuju text intro & $\begin{array}{l}\text { [〕] Berhasil } \\
\text { [] Tidak berhasil }\end{array}$ \\
\hline \multirow{3}{*}{6} & \multirow{3}{*}{ Tampilan Berhasil } & Memilih tombol menu & Menuju menu awal game & $\begin{array}{l}\text { [〕] Berhasil } \\
\text { [] Tidak berhasil }\end{array}$ \\
\hline & & Memilih tombol main lagi & $\begin{array}{l}\text { Menuju tampilan memulai } \\
\text { game }\end{array}$ & $\begin{array}{l}\text { [ }] \text { Berhasil } \\
\text { [] Tidak berhasil }\end{array}$ \\
\hline & & Memilih tombol lanjut & Menuju level selanjutnya & $\begin{array}{l}\text { [ }] \text { Berhasil } \\
\text { [] Tidak berhasil }\end{array}$ \\
\hline
\end{tabular}

\section{B) Saran}

Dengan memperhatikan hasil perancangan software Game Aritmetika "Keong math" ini, saran yang diberikan sebagai berikut :

1. Dalam pembuatan software game aritmetika ini harus memperhatikan sasaran dan batasan sebelum pengujian sistem.

2. Software game ini harus mempunyai parameter sendiri sebagai ukuran keberhasilan sistem multimedia, dan melakukan pemeliharaan sistem dengan melakukan evaluasi untuk menentukan apakah sistem sesuai harapan semula dan apakah masih ada revisi atau modifikasi.

\section{DAFTAR PUSTAKA}

Kamus Bahasa Indonesia Online, 28 Agustus 2014.

Diperoleh dari :

http://kamusbahasaindonesia.org/analisis

Departemen Pendidikan Nasional (2004), Kamus Besar Bahasa Indonesia Pusat Bahasa Edisi ke Empat, PT.Gramedia Pustaka Utama, Jakarta 10270 
Sutopo, (2003) Pengertian Multimedia, Mahir Macromedia , diperoleh 27 Agustus 2015 dari http://www.baliorange.web.id/pengerianMultimedia

Teknik Pengujian Perangkat Lunak, 29 Oktober 2015.

http://rifiana.staf.gunadarma.ac.id/download/fi les

Tutorial Animasi Flash 8, 28 Oktober 2015 dari http://avies.staff.mipa.uns.ac.id

Tutorial Macromedia Flash professional 8, 28 Oktober 2015.

http://icmgi.file.wordpress.com

Pembuatan Animasi dengan Macromedia Flash 8, 29

Oktober 2015. dari

http://handriyo-tvf.dosen.isi-ska.ac.id 